\title{
4. ZWISCHEN KUNST, KRITIK UND KOMMERZ GRUNDZÜGE DER SATIRISCHEN BILDPUBLIZISTIK IN FRANKREICH (1871-1914)
}

\author{
4.1. » ̀̀ propos de la loi sur la presse: Tant de choses \\ qui se passeraient dans l'ombre si elle n'éclairait pas! \\ Bildsatire und Zensur (1871-1881)
}

Karikatur und Karikaturist sind als Produkte ihrer Zeit nur vor den wechselnden politischen und gesellschaftlichen Hintergründen zu verstehen und zu erklären. In dieser Hinsicht stellt die III. Republik mit ihren sich bis zum Ersten Weltkrieg kontinuierlich aufsplitternden politischen Überzeugungen und Gruppierungen ein besonders kompliziertes Untersuchungsobjekt dar. Zu der traditionellen politischen Karikatur, die sich direkt mit Entscheidungsträgern und ihrem Tun befaßt, tritt zudem mehr und mehr die sozialkritische Karikatur, die auch nach einer Modifizierung des Begriffs der Bildsatire verlangt.

Die Entwicklung der Presse seit $1871^{1}$ geht dabei mit den sich verändernden und erweiternden Perspektiven der Karikatur und ihrer Anliegen Hand in Hand. Die Frühzeit der III. Republik stellte zunächst keinen Fortschritt in Richtung auf eine freie Presse dar. Als am 18. März 1871 die erst ein Jahr zuvor, am 30. März 1870, abgeschaffte Zensur der Karikatur erneut eingeführt wurde ${ }^{2}$, schien dies zunächst eine allein gegen die Commune gerichtete Maßnahme zu sein, die eine Vielzahl von ephemeren Zeitungen und Zeitschriften hervorgebracht hatte ${ }^{3}$.

1 Allg. zur Presse unter der III. Republik vgl. Raymond Manevy, La presse de la III ${ }^{e}$ République, Paris 1955; Claude Bellanger, ( Hg.), Histoire générale de la presse française, Bd.3: 1871-1914; Marc Martin, Médias et journalistes de la République, Paris 1997. Zu soziokulturellen Aspekten vgl. Christian DelPorTE, Presse et culture de masse en France (1880-1914), in: Revue historique 122 (1998), S.91-121; Jean-Yves Mollier, Le parfum de la Belle Époque, in: Jean-Pierre Rioux, Jean-François SiRINelli (Hg.), La culture de masse en France de la Belle Époque à aujourd'hui, Paris 2002, S.72-115, sowie Élisabeth Parinet, Une histoire de l'édition à l'époque contemporaine ( $\mathrm{XIX}^{\mathrm{e}}-\mathrm{XX}^{\mathrm{e}}$ siècle), Paris 2004. Speziell zur Frühzeit der politischen Presse in der III. Republik vgl. Pierre AlberT, Histoire de la presse politique nationale au début de la Troisième République (1871-1879), 2 Bde., Lille, Paris 1979. Zur satirischen Presse 1871-1914 allg. vgl. Bargeton, Typologie, sowie WaTELET, La presse illustrée.

2 Jacques Lethève, La caricature sous la III ${ }^{e}$ République, Paris ${ }^{2} 1986$, S.22; Robert J. Goldstein, Censorship of Political Caricature in Nineteenth-Century France, Kent, London 1989, S.202; TILlier, Traits indécis, S. 87.

${ }^{3}$ Dazu das Verzeichnis von Firmin MaIllard, Histoire des journaux publiés à Paris pendant le siège et sous la Commune du 4 septembre 1870 au 28 mai 1871, Paris 1871. Allg. zur Presse unter der Commune vgl. Aimé Dupuy, 1870-1871. La guerre, la Commune et la presse, Paris 1959. Die Karikatur wurde während der Commune in erster Linie auf Flugblättern verbreitet, die dabei gleichzeitig ihre letzte große Blütezeit erlebten. Dazu auch 
Nach den Wahlen am 2. Juli jedoch stellte sich schnell heraus, daß die Zensur des satirischen Bildes sich auch gegen die bürgerlich-republikanische Karikatur richtete, wie das Magazin Le Grelot, das sich vehement gegen die Commune engagiert hatte ${ }^{4}$.

In den folgenden zehn Jahren sollte die Zensur von den wechselnden Regierungen in einer Weise benutzt werden, die zum Spiegel der höchst unsicheren politischen Lage wurde: Solange die Republik selbst in ständiger existenzbedrohender Gefahr zu schweben schien, galt dies auch für die kritische Pressezeichnung.

Unter diesen Bedingungen wurde die Zensur der Presse zeitweise ein wichtigeres Bildthema als die Politik selbst ${ }^{5}$, um so mehr als sich unter der restriktiven Regierung des ordre moral in den Jahren 1873 bis 1877 das potentielle Themenfeld immer mehr einengte. So rückte der Mythos von der Presse selbst als bedrohter Lichtmacht in den Vordergrund ${ }^{6}$. Exemplarisch dafür steht eine Illustration, die Charles Gilbert-Martin als Ersatz für ein von der Zensur verbotenes Bild für seine Zeitschrift Le Don Quichotte schuf, die in Bordeaux erschien und dort besonders starken Repressalien ausgesetzt war ${ }^{7}$. Das Frontispiz vom 19. Juni $1875^{8}$ zeigt, sinnigerweise unter dem Titel Improvisation ${ }^{9}$, eine Kerze über deren Flamme sich gerade eine Hand mit einem Löschhütchen gesenkt hat. Die Position des Kerzenhalters auf einem Buch, dessen Rücken die Aufschrift enseignement trägt, hebt den dargestellten Konflikt weit über die Auseinandersetzung zwischen Zensor und Karikaturist hinaus. Das Problem der instruction ${ }^{10}$ verschmilzt vielmehr mit dem Akt der

Tillier, Traits indécis, S. 87: »Avec la déchéance de l'Empire et la proclamation de la République [...], la libéralisation de la presse et de la caricature - mais aussi, du même coup, du colportage, de l'affichage et de l'édition - provoqua une avalanche d'images satiriques".

${ }_{4}^{4}$ RoberTs-Jones, De Daumier à Lautrec, S.31. Zur Darstellung der Commune in Le Grelot vgl. bes. Kap. 5.2.

${ }^{5}$ Zur Spiegelung der Pressezensur in der Bildpublizistik der frühen III. Republik ausführlich: GoldSteIn, Censorship, S. 202-257. Vgl. auch Philippe RoBerts-Jones, La caricature du Second Empire à la Belle Époque, Paris 1963; Jean Garrigues, Images d'une transition: Quelques réflexions sur les dessins satiriques en France de 1870 à 1877, in: Hélène DuCcinI, Jean-Claude Gardes ( $\mathrm{Hg}$.), L'image satirique face à l'innovation, Paris 1996, S. 93-111; Christian Brebeck, Die politische Karikatur in Frankreich von 1867 bis 1879, in: Ders., Gilbert Charmeil (Hg.), Die Entstehung der Dritten Republik in der Karikatur, Bonn 1992, S. 8-12.

${ }^{6}$ Dies thematisierte schon Honoré Daumier 1850 in seiner Karikatur Le Parricide. Vgl. dazu Kap.3.2.2.

7 GoldsteIn, Censorship, S.207-209. Allein zwischen Mai 1877 und März 1878 wurde Le Don Quichotte zwölf Mal gerichtlich belangt.

8 Ibid., S.215, Abb. 64. Erwähnt auch bei Garrigues, Images, S. 104.

${ }^{9}$ Charles GilberT-Martin, Improvisation, in: Le Don Quichotte, 19.6.1875. Der Untertitel vervollständigt: „En remplacement d'un dessin interdit par la censure«. Abgebildet bei Goldstein, Censorship, S. 215.

${ }^{10}$ Zur instruction obligatoire vgl. Kap.6.2. 
Zensur zu einer Anklage gegen die Unterdrückung der geistigen Freiheit. Wie unmittelbar beides aufeinander aufbaut, wird hier modellhaft gezeigt: Die >ausgelöschte $\times$ Presse kann nicht mehr als Informationsquelle fungieren, ebenso wie fehlende Bildung dem einzelnen die Möglichkeit nimmt, diese Quelle zu nutzen.

Schon der Name der personifizierten Zensur, Anastasie, abgeleitet von dem griechischen Wort für Auferstehung, spielte auf die unablässige, bedrohliche Wiederbelebung des schon so oft tot geglaubten restriktiven Instruments an ${ }^{11}$.

Am 19. Juli 1874 verlieh André Gill ihr in L'Éclipse erstmals eine Gestalt: Madame Anastasie erscheint als alte Hexe mit einer Eule auf der Schulter, einem unverkennbaren Finsternissymbol ${ }^{12}$ :

Anastasie, c'est l'obscurité, l'obscurantisme [...]. Ce sont les peurs et les fanatismes d'un autre âge. La chouette qui l'accompagne [idée de Gill] n'est pas là seulement pour prêter la flanc à la formule ironique [>la vieille chouette‘]. Elle symbolise la nuit, le maléfice, la sorcellerie, les superstitions d'un âge reculé ${ }^{13}$.

Besonders im Kontext von L'Éclipse, dessen noch unter dem Empire gewählter Titel ja eine direkte Reaktion auf die Zensur darstellte, wird dies bedeutsam: Im Oktober 1865 hatte Gill sein erstes satirisches Magazin La Lune gegründet $^{14}$, mit dem zugleich eine neue Ära der politischen Karikatur begann. Die Titelgebung spielte auf die kurz zuvor erstmals erschienene, der Regierung nahestehende Zeitung Le Soleil von Polydor Millaud an. In der ersten Ausgabe der konsequent auf schwarzem Papier gedruckten La Lune hieB es dazu: »à lui le Soleil, à nous la Lune, à lui le jour, à nous la nuit « ${ }^{15}$.

Das Bild des Mondes fungiert zugleich als Nachtlicht, das die umgebende Finsternis nicht vertreiben, aber doch aufhellen kann. Als La Lune am 17. Januar 1868 sein Erscheinen einstellen mußte, blieb als einziger Ausweg eine Neugründung - die genau zwei Monate später unter dem Titel L'Éclipse er-

11 Dazu Christian Delporte, Anastasie: l'imaginaire de la censure dans le dessin satirique ( $\mathrm{XIX}^{\mathrm{e}}-\mathrm{XX}^{\mathrm{e}}$ siècle), in: Pascal $\mathrm{ORY}(\mathrm{Hg}$.), La censure en France à l'ère démocratique (1848-1994), Brüssel, S. 92: »Anastasie représente la censure qu'on croit toujours enterrée et qui, sans cesse, ressuscite (en $1803,1814,1820,1835,1852 \ldots$ ). Reprenant vie, elle jaillit des profondeurs des ténèbres pour masquer la lumière de la liberté«.

12 Zur Eule als Finsternissymbol vgl. Heinrich Schwarz, Volker Plagemann, Eule, in: Reallexikon zur deutschen Kunstgeschichte, hg. v. Zentralinstitut für Kunstgeschichte München, 10 Bde., Stuttgart u.a. 1937-2003, Bd.6 (1973), S. 267-322; P. VANDENBRoECK, Bubo significans. Die Eule als Sinnbild von Schlechtigkeit und Torheit, in: Jaerboek van het Koninklijk Museum voor Schone Kunsten, 1985, S. 19-135.

13 Delporte, Anastasie, S. 95.

$14 \mathrm{Zu}$ La Lune ausführlich Charles FonTANe, Un maître de la caricature: André Gill, Paris 1928, Bd. 1, S. 176-229. Vgl. auch Jones, Presse satirique, S.82f.

15 Zitiert nach Fontane, Maître, Bd.1, S.176. Vgl. dazu auch die Ankündigung des neuen Magazins: »LA LUNE, journal nocturne à l'usage des noctambules, paraissant à minuit « (ibid., S. 177). 
folgte $^{16}$ und sich unmißverständlich auf die versuchte >Auslöschung des kritischen Vorgängers bezog ${ }^{17}$. Nichts könnte besser als die Verbildlichung der Zensur mit dem Attribut der Eule veranschaulichen, daß diese Verfinsterung in der Republik noch weiter andauerte. Auch die Namensgebungen von Gills folgenden Neugründungen bewegen sich im Rahmen dieser Bildsprache. 1876 zog der längst legendäre Karikaturist sich von L'Éclipse zurück, die ab Juni als nouvelle série in einem kleineren Format erschien und sich noch bis 1919 der Gesellschafts- und Sittenkarikatur widmete. Am 10. Dezember 1876 erschien dagegen die erste Nummer von Gills neuem Blatt La Lune rousse, das in den drei Jahren seiner Existenz einen unablässigen Kampf mit der Zensur provozierte $^{18}$. Der Titel nahm - wie auch die 1878 bis 1879 erschienene Zeitschrift La Petite Lune - direkt Bezug auf das Vorbild La Lune und übte so auch immanent Kritik an der immer noch auf die Rolle eines $>$ Nachtlichts reduzierten Karikatur im Angesicht der Zensur ${ }^{19}$.

${ }^{16} \mathrm{Zu}$ L'Éclipse ibid., S.229-311, sowie Bd.2, S.1-85. Vgl. auch Jones, Presse satirique, S.53f. Zu La Lune und L'Éclipse im II. Empire vgl. Roger BELlet, Drei Jahre Karikaturen von André Gill: »La Lune « und »L'Éclipse« von 1867 bis 1869, in: Raimund RürTEN u. a. (Hg.), Die Karikatur zwischen Republik und Zensur, S.408-414. Davon abgesehen fand die Lichtsymbolik im Titel satirischer Zeitschriften wenig Nachfolge, doch auch die Tageszeitung L'Aurore und das literarisch-künstlerische Magazin L'Aube bedienten sich dieser Bildsprache. Bei den journaux satiriques blieb dagegen die Tradition der Lautmalerei sehr stark, wie sie schon im Titel von Le Charivari (Katzenmusik) zum Ausdruck kam. So etwa Le Grelot (Die Schelle), Le Sifflet (Die Pfeife), Le Pétard (Der Knallfrosch).

${ }^{17}$ Nichtsdestoweniger spielte Gill auch in L'Éclipse weiterhin mit dem Motiv des Lichts in der Dunkelheit, das trotz aller Löschversuche unvermindert leuchtet. So am 12.12.1869 in der Karikatur Le Dégel, die den Kaiser als im Mondlicht (!) dahinschmelzenden Schneemann zeigt, ausgestattet mit einem Löschhütchen an langer Stange, das durch seine drohende Annäherung an den Mond die Gefahr der völligen Verdunkelung auch im Moment des Sturzes noch vor Augen führt, sowie den Zensurattributen Schere und Schlüssel. Der Untertitel Derniers jours de l'Empire bringt die - in der Republik zunächst enttäuschte Hoffnung zum Ausdruck, das Ende des Empire und das Ende der Zensur seien gemeinsam zu erwarten.

${ }^{18} \mathrm{Zu}$ La Lune rousse vgl. Fontane, Bd.2, S. 89-146. Bis 10.12.1876 erschienen 159 Ausgaben. $\mathrm{Zu}$ La Lune rousse und der Zensur vgl. GoldsteIn, Censorship, S.209. In diesem Zusammenhang werden auch mögliche 'Schlupflöcher ‘ für die kritische Karikatur sichtbar: Im August 1877 wurde in La Lune rousse eine Zeichnung von Gill zensiert, die, laut Goldsteins Beschreibung einen Napoleon III. ähnelnden Mann zeigt, der vor einem schwachen Kerzenlicht auf einer Klarinette spielt. Eine sehr ähnliche, möglicherweise identische Zeichnung von André Gill erschien nichtsdestoweniger ungehindert in einer der ersten Nummern der unpolitischen nouvelle série von L'Éclipse am 13.8.1876 unter dem Titel Quinze Août. Vgl. dazu Kap.7.1.1., Abb.41. Auch die nicht erschienene Karikatur - die wie viele andere in einer der folgenden Ausgaben detailliert beschrieben wurde - bezog sich wohl auf das Datum des 15. August. Vgl. dazu Kap.7.1.1.

19 Im Jahr 1880 arbeitete Gill zudem für die von Heymann gegründeten Zeitschrift $L a$ Nouvelle lune, die bis 1893 bestand. Das eigentliche Ende der Pressezensur erlebte Gill, der seit 1881 in zunehmender geistiger Umnachtung vegetierte, nicht mehr. Zur Situation der Karikatur 1878 bis 1881 vgl. allg. Gonzalo J. SánCHEZ, The Challenge of Right-Wing Caricature Journals: From the Commune Amnesty Campaign to the End of Censorship, in: French History 10 (1996), S. 451-489. 
Die unverzichtbare Rolle der Presse als kontrollierender und informierender Instanz thematisierte noch zwei Monate vor dem versuchten antirepublikanischen Staatsstreich von Präsident Mac-Mahon im Mai 1877 eine kleine Karikatur von Cham in Le Charivari ${ }^{20}$ : Der Künstler zeigt die Presse als weibliche Allegorie, die in der hoch erhobenen Hand eine brennende Kerze hält, mit der sie in die Welt hineinleuchtet: »À PROPOS DE LA LOI SUR LA PRESSE: Tant de choses qui se passeraient dans l'ombre si elle n'éclairait pas! (En tenir compte) «. Der Kunstgriff des Kommentars liegt darin, die Freiheit der Presse vordergründig nicht anzuzweifeln: Unter dem Schutz einer reinen Hypothese - was passieren würde, wenn die Presse nicht aufklären würde - wird auf die reale Situation verwiesen. Der Zusatz en tenir compte - »was zu beachten ist « - spielt dagegen klar auf eine erwartete mögliche Verschlimmerung der Situation an: Die lichtspendende Funktion der Presse sollte man sich also vor Augen halten, ehe man ihre Möglichkeiten weiter einschränkt und sich somit selbst der Dunkelheit preisgibt.

Der Sieg der Republikaner bei den Wahlen im Oktober 1877 verbesserte die Lage der republikanischen Karikatur jedoch zunächst ebensowenig wie der Rücktritt von Mac-Mahon und seiner im Kern monarchistischen Regierung des ordre moral Ende Januar $1879^{21}$.

Bis 1881 fühlten die republikanischen Regierungen sich offenbar noch zu unsicher, um die Zügel locker zu lassen ${ }^{22}$. Zeitgleich wurde die Republik mit einer neuen Herausforderung konfrontiert: Die Karikatur von rechts, verkörpert in erster Linie durch die im November 1878 gegründete royalistischlegitimistische Satirezeitschrift Le Triboulet wurde als sehr ernstzunehmende Gefahr eingeschätzt ${ }^{23}$ : Zwischen April 1879 und Juli 1881 wurde Le Triboulet allein $37 \mathrm{Mal}$ juristisch belangt $t^{24}$. Das Magazin verstand seine Rolle dabei ebenfalls ganz in der Tradition der Presse als lichtverbreitender Instanz. Zwei Karikaturen aus jener Zeit von Blass stellen dies auf anschauliche Weise dar. Die Figur des mittelalterlichen Hofnarren, an die der Zeitschriftentitel anknüpft, fungiert dabei jeweils als Kämpfer gegen dunkle Mächte: Auf einer Abbildung von 1879 blendet der Narr mit einer Laterne das sprichwörtliche spectre rouge ${ }^{25}$, das als flache Hampelmannfigur in seiner Bedrohlichkeit allerdings weit reduziert ist: À l'abri, nous autres, des attaques nocturnes! ${ }^{26}$

20 Ausgabe vom 11.3.1877. Die Karikatur ist Teil der Skizzenfolge Croquis par Cham, die auf einer Seite zwölf kleinformatige Bilder mit unterschiedlicher Thematik präsentiert. Es ist möglich, daß diese in Le Charivari regelmäßig erscheinenden croquis verschiedener Künstler von der Zensur weniger streng geprüft wurden.

21 RoberTs-Jones, De Daumier à Lautrec, S.37: $\$ 1879$ [...] voit tout autant de dessins refusés, de saisies et de condamnations «.

22 Goldstein, Censorship, S.219f.

23 Ibid., S. 231.

24 Ibid., S. 226. Zu Le Triboulet vgl. auch SÁNCHEZ, Challenge, S. 462-467.

${ }_{25}$ Zum spectre rouge und seiner Reduzierung zur Holzfigur vgl. Kap. 5.3.

26 Ausgabe vom 23.2.1879 (Hervorhebung im Original). 
Der Pinsel in der Hand des Triboulet weist die Hauptrolle bei der Verteidigung gegen die finsteren Angreifer der Karikatur zu - ein deutlicher Hinweis darauf, daß die royalistische Oppositionspresse die Zeichen der Zeit erkannt hatte und wenige Monate nach ihrer Gründung bereit war, in den Bilderkampf einzugreifen. In einer Darstellung von Blass am 14. November 1880 präsentiert sich der mittlerweile zu einer idealisierten Figur gereifte, mit einer riesigen Schreibfeder bewaffnete Triboulet als mächtiger Gegner der ihn umflatternden Fledermäuse ${ }^{27}$, die unter anderem die Köpfe von Léon Gambetta und Jules Ferry tragen. Diese Komposition lehnt sich eng an das Motiv der vom Kerzenlicht angezogenen und gleichzeitig verbrannten Nachtfalter an, das zum verbreiteten Repertoire der Lichtsymbolik gehörte ${ }^{28}$. Der Narr wird also zur wahrhaftigen Lichtgestalt, der die Mächte der Finsternis hilflos gegenüberstehen. Daran, daß Le Triboulet auch in Zukunft - trotz Zensur - ein ernstzunehmender Gegner sein werde, läßt der Bildtext keinen Zweifel: »Un gaillard qui fera carrément son chemin«.

Das Motiv der Lichtverbreitung spiegelt auch die Illustration, mit der Le Charivari das Jahr 1880 - und das 49. Jahr seines Erscheinens - einleitete ${ }^{29}$. Die weibliche Allegorie des zu diesem Zeitpunkt längst legendären Magazins trägt nicht nur eine Peitsche in der Hand, die für die Schärfe der karikaturistischen Kritik steht, sondern auch eine Laterne, die das Aufklärungsverständnis des Blattes symbolisiert ${ }^{30}$.

Der entschiedene Wille der Presse, aktiver zur Meinungsbildung beizutragen, konfrontierte die Republik in der Phase von 1878 bis 1881 folglich mit zwei Problemen: Zum einen mit der Frage nach dem Umgang mit der prorepublikanischen Bildkritik, zum anderen mit der Toleranzschwelle gegenüber der antirepublikanischen Opposition. Die Akzeptanz dieser Kritik gehört unmittelbar zum demokratischen Reifungsprozeß der Republik: Seit 1879 arbeitete eine Kommission an der Formulierung eines neuen, liberalen Pressegesetzes. Gleichzeitig änderte sich auch die Haltung gegenüber der Karikatur: Im Juli 1880 verurteilte der Innenminister Jean Constans bei einer Debatte scharf die Zensur von Pressezeichnungen und kündigte das baldige Ende dieser Praxis an. Dieses Versprechen wurde schließlich mit der loi sur la presse

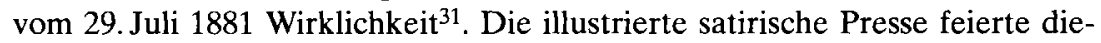

27 Zur Fledermaus als Finsternissymbol vgl. Peter LuH, Fledermaus, in: Reallexikon zur deutschen Kunstgeschichte, Bd.9 (1995), S.980-1043.

${ }^{28}$ Dazu vielfältige Beispiele in den folgenden Kapiteln.

29 Unsigniert: $1^{e r}$ janvier 1880, in: Le Charivari, 1.1.1880: "Bonjour et puis bon an / Qu'heureuse et longue vie / Soit ton lot, cher lecteur, fidele à m'accueillir! / Pour te remercier, ton journal te convie / A trouver, comme lui, du plaisir à vieillir «.

30 Zur Geschichte von Le Charivari in der III. Republik vgl. Koch, SAGAVE, Le Charivari, S. 255-369.

31 Vgl. zu diesem Gesetz Fernand Terrou, Lévolution du droit de la presse de 1881 à 1940, in: Bellanger, Histoire, S.7-57; Pierre Alberr, La presse française de 1871 à 1940, in: BeLlanger, Histoire, S. 240-243. 
ses Ereignis mit Darstellungen, die das endgültige Ende, häufig die definitive Hinrichtung von Anastasie zeigten ${ }^{32}$ : Ein neues Zeitalter war damit eingeläutet, dessen neue Freiheiten gleichzeitig neue Herausforderungen bedeuten sollten.

32 Dazu Goldstein, Censorship, S. 232-235. Moloch schuf beispielsweise für La Silhouette (4.4.1881) eine Zeichnung, auf der Anastasie noch während ihrer >Arbeit - die darin besteht, Zeichnungen zu zerschneiden - von der knochigen Hand des Todes ihrerseits mit der Sense loi sur la presse geköpft wird. 


\section{2. »Âge d'or « zwischen Licht und Finsternis Wandlungsprozesse im Verhältnis von politischer und gesellschaftskritischer Karikatur (1881-1914)}

Welche Auswirkungen hatte das Gesetz von 1881 auf die Karikatur? Begann nun tatsächlich das sogenannte >goldene Zeitalter « der illustrierten satirischen Presse, oder galt dies nur für die nicht-politische, unterhaltende bis frivole Karikatur? Ein Blick auf die Rezeptionsgeschichte des Begriffs soll zur Klärung dieser Fragen beitragen: Philippe Jones, auf den die vielzitierte Bezeichnung des âge d'or zurückgeht, umschrieb damit ursprünglich die Jahre von 1860 bis $1890^{33}$. Für die politische Karikatur, deren Renaissance im II. Empire mit der 1865 gegründeten La Lune beginnt, setzte Jones das Ende der Blütezeit dagegen definitiv mit der Aufhebung der Zensur durch die loi sur la presse von 1881 an: »Mais il est curieux de noter que, si cette caricature se meut plus librement, elle perd de son intérêt dans une certaine mesure. Étant moins menacée, elle devient moins inventive et moins subtile « ${ }^{34}$. Die Einschätzung, daß nach dem Ende der Zensur für die politische Karikatur eine Ära des Niedergangs begonnen hätte, findet sich schon bei den Zeitgenossen ${ }^{35}$. Émile Bayard schrieb 1900: »La caricature ne vise plus à la satire, il est vrai; l'entière liberté de la presse paralyse ses moyens $\aleph^{36}$. Derartige Urteile über die Karikatur der III. Republik wurden stets im direkten Vergleich mit vorangegangenen Epochen gefällt, allen voran der Zeit von 1830-1835 und der Revolution von 1848, die ihrerseits am Vorabend der III. Republik als Kunstwerk und historische Quellen gleichermaßen entdeckt und erforscht wurden ${ }^{37}$. Vor allem

33 Vgl. Jones, Presse satirique, S. 7: "La création d'une presse satirique illustrée est un événement dont l'importance ne peut être réellement mesurée qu'entre 1860 et 1890 période durant laquelle cette presse vécut son âge d'or «. Er begründete diese zeitliche Definition mit der ab 1860 deutlich zu verzeichnenden Zunahme an zunächst der Gesellschaftskarikatur gewidmeten Satiremagazinen.

34 Ibid., S. 10. Das Primat sieht Jones ab den 1880er Jahren wiederum bei der Sittenkarikatur.

35 Weitere Beispiele bei Goldstein, Censorship, S. 236f.

36 Émile Bayard, La caricature et les caricaturistes, Paris 1900, S.21. Die hier deutlich werdende Unterscheidung zwischen der als politisch interpretierten Satire und dem Sammelbegriff »Karikatur « findet sich auch im parallel erschienenen Werk von Adolphe BRISSON, Nos humoristes, Paris 1900. Dieser verwendet für die Klassifizierung der Künstler zwar den Oberbegriff humoristes, hebt jedoch gleichfalls den satiriste deutlich hervor: »En ceux-là se concentre ce qu'il y a de plus aigu et aussi de plus profond dans l'esprit national. Ils forment une glorieuse lignée. [...] Daumier les domine, de toute la hauteur de son génie«. (ibid., S.VI.). Demgegenüber tritt die Leistung des caricaturiste stark zurück: »Il s'adresse aux yeux plutôt qu'à l'esprit. Il divertit, il fait rarement penser «, ibid., S. IV.

${ }^{37}$ Die Entdeckung der Karikatur als Forschungsgebiet begann in Frankreich mit Jules de Champfleury, Histoire de la caricature moderne, Paris 1865. Das Werk ist der Epoche von 1830-1860 gewidmet, wobei Honoré Daumier im Mittelpunkt steht. (Zu Champfleury und der Karikatur vgl. Francis Haskell, Die Geschichte und ihre Bilder, München 1995, 
Honoré Daumier wurde nicht nur zum genuin republikanischen Künstler erhoben, sondern gezielt zum Mythos stilisiert ${ }^{38}$. Eine Vorwegnahme dessen stellten schon Baudelaires 1857 veröffentlichte enthusiastische Notizen über Daumier dar, die zugleich eine verschlüsselte Hommage an den Wert der Karikatur als Mittel der politischen Opposition waren ${ }^{39}$.

Ihren eigentlichen Anfang nahm die Konstruktion des Mythos Daumier jedoch mit der ersten Retrospektive seines Werkes 1878 in Paris, die darüber hinaus noch einen anderen Effekt hatte: die satirische Pressezeichnung wurde zum neuen Interessengebiet von Sammlern und Kunsthändlern ${ }^{40}$. Dabei scheint es, als sei die politische Karikatur gerade dadurch auf ein kaum mehr zu erreichendes, gleichsam entrücktes und daher unpolitisches, sich der Aktualität verschließendes Niveau angehoben worden. Der Bilderkrieg, den Daumier und seine Zeitgenossen gegen Louis-Philippe und später gegen die Avancen des künftigen Napoleon III. geführt hatten, wurde zwar als nicht wiederholbar erkannt, aber schließlich gerade deshalb verklärt. Eduard Fuchs schrieb 1908 über den Charakter des Generationenwechsels:

Genie und Talent in enormen Mengen bringt die moderne Karikatur, nur eines fehlte freilich sehr häufig - das Merkmal der Zeit: die unwandelbare Gesinnung, die fest gegründete

S. 396-400: Haskells Schlußfolgerung, daß Champfleury die Karikatur als eine dem Untergang geweihte Gattung betrachtet, ist allerdings falsch. Champfleury betont vielmehr: "Elle ne meurt jamais" [Préface, S. VIII] und vergleicht die Karikatur mit einer schlafenden Katze, die bei der kleinsten politischen Veränderung wieder zum Leben erwachen würde. Vermutlich wußte Haskell, der die zweite Auflage von 1871 verwendete, nicht, daß das gleichlautende Vorwort bereits in der Erstausgabe von 1865 abgedruckt war und sich folglich auf die unter der Zensur des II. Empire zum Erliegen gekommene politische Karikatur bezieht und nicht auf die Gattung selbst.) Parallel zu diesem Interesse an Ursprung und Entwicklung der Karikatur als Gattung rückte sie auch als zeitgeschichtliche Quelle ins Blickfeld. Exemplarisch hierfür steht das frühe Interesse an der Karikatur der Commune: Vgl. dazu etwa E. Money, La Caricature sous la Commune, in: Revue de France 2 (1872), S.33-54.

38 Zur Rezeptionsgeschichte von Daumier in der III. Republik vgl. Michel MeLor, Daumier and Art History: Aesthetic Judgment / Political Judgement, in: The Oxford Art Journal 11 (1988), bes. S.3-13.

39 Charles Baudelaire, Quelques caricaturistes français, in: Ders., Euvres complètes, Bd.2, Paris 1976, S.544-563. Besonders die detaillierte Beschreibung von Daumiers berühmter Graphik Liberté de la presse mutet wie ein Protest gegen die Pressezensur unter dem Empire an. Vgl. ibid., S. 553: "Je me rappelle encore un fort beau dessin qui appartient à la même classe: La Liberté de la presse. Au milieu de ses instruments émancipateurs, de son matériel d'imprimerie, un ouvrier typographe, coiffé sur l'oreille du sacramentel bonnet de papier, les manches de chemise retroussées, carrément campé, établi solidement sur ses grands pieds, ferme les deux poings et fronce les sourcils. Tout cet homme est musclé et charpenté comme les figures des grands maîtres. Dans le fond, l'éternel Philippe et ses sergents de ville. Ils n'osent pas s'y frotter «. (Der Untertitel der im März 1834 in L'Association mensuelle erschienenen Karikatur lautet: Ne vous y frottez pas!)

${ }^{40}$ Vgl. dazu Melot, Daumier, S.3. Zur Bewunderung der Karikaturisten des späten 19. Jahrhunderts für Daumier vgl. zahlreiche Zitate bei Brisson, Nos humoristes, so beispielsweise den Kommentar von Hermann-Paul: „Quel maître! [...] On ne se lasse pas de l'admirer!« (ibid., S.45). 
Überzeugung, das, was das Werk eines Daumier so groß machte und aller Zeiten Geschmack überdauern lassen wird ${ }^{41}$.

Émile Bayard bemerkte zum Problem der Übertragbarkeit im Jahr 1900 dagegen treffend:

Chaque génération, du reste, adopte une manière de caricature politique. Cette manière, relevant autant de la vie courante que de l'art, sombre en même temps que la génération qui la vit naître. Elle est aussi éphémère que les hommes qu'elle caractérisait ${ }^{42}$.

Tatsächlich scheint es im Vergleich zur Julimonarchie ungleich schwieriger, in der III. Republik eine spezifische manière de caricature politique auszumachen. Heißt dies aber automatisch, daß sie, wie Goldstein noch 1989 urteilte, im Niedergang begriffen war ${ }^{43}$ ?

Unbestritten ist, daß die politische Karikatur auch nach 1881 keineswegs frei von Beschränkungen war. Darstellungen, die als beleidigend für den Präsidenten oder die Armee angesehen wurden, konnten auch nach der Veröffentlichung noch strafrechtlich verfolgt werden ${ }^{44}$. Der spektakulärste Fall ist dabei zweifellos der des Karikaturisten Aristide Delannoy, der im Jahr 1908 General d'Amade als Schlachter darstellte und dafür zu zwei Jahren Gefängnis und einer Geldstrafe von 6000 Francs verurteilt wurde ${ }^{45}$.

Einen erheblichen Eingriff in die Pressefreiheit stellten überdies die als $\mathrm{Re}$ aktion auf die Ära der anarchistischen Attentate und die Ermordung von Präsident Sadi Carnot erlassenen sogenannten lois scélérates dar, die für mehrere Jahre das vorläufige Aus der anarchistischen Presse bedeuteten ${ }^{46}$. Von diesen spektakulären Fällen abgesehen, muß auch die Erprobung der verlockenden neuen Freiheit als wichtiges Element in der Pressegeschichte berücksichtigt werden: Die unmittelbarste Folge des Gesetzes von 1881 war eine Flut von neuen illustrierten Magazinen mit häufig frivolem bis pornographischem

41 Eduard Fuchs, Die Karikatur der europäischen Völker, Bd. 2: Vom Jahre 1848 bis zum Vorabend des Weltkrieges, München ${ }^{4} 1921$, S. 351. (Die Ausgabe von 1921 ist eine unveränderte Neuauflage der Erstausgabe von 1908. Lediglich der Titel wurde durch die Nennung des Weltkrieges erweitert.)

42 BAYARD, Caricature, S. 21.

43 Goldstern, Censorship, S. 229: "The End of Censorship and the decline of political caricature«. Vgl. zum Problem des Daumierschen Erbes auch Tillıer, Traits indécis, S. 93: "Le journal illustré et le dessin de presse des années 1870 à 1914 sont en effet considérés comme les marqueurs d'un affaiblissement, d'une édulcoration ou d'un abâtardissement de formules héritées du premier XIX ${ }^{e}$ siècle. L'historiographie de ces objets trouva longtemps ses références chez Daumier. Après la mort de Daumier en 1879, la plupart des dessinateurs furent considérés comme inférieurs au maître, jugé inégalable«.

44 Goldstein, Censorship, S. 239.

45 Lethève, Caricature, S.36. Auch während der Jahre 1886 bis 1889 wurden im Zusammenhang mit der Boulangerkrise militärkritische Bilder geahndet. 1888 wurde in diesem Zusammenhang der für Boulanger eintretende Karikaturist Alfred Le Petit zu einer Gefängnisstrafe verurteilt, was gleichzeitig die erste derartige Maßnahme seit Abschaffung der Zensur darstellte. Goldstein, Censorship, S. 239.

46 Terrou, Évolution, S. 25. Dazu ausführlich Kap. 9.2.1. 
Charakter, was 1882 die loi sur les publications obscènes zur Folge hatte ${ }^{47}$. Hierbei drängt sich der Eindruck auf, daß dies auch zum Vorwand genommen wurde, um gegen allzu sittenkritische Satiremagazine vorzugehen. Der tendenziell anarchistische Le Courrier français, eines der künstlerisch progressivsten Blätter der 1880er Jahre, wurde aus diesem Anlaß mehrfach belangt. Besonders mehrere Beiträge des anerkannten Künstlers Louis Legrand, die auf drastische Art und Weise die Ausbeutung der Prostituierten anprangerten, wurden als pornographisch verfolgt, Legrand selbst mehrfach zu Geldstrafen und schließlich zu zwei Monaten Gefängnis verurteilt ${ }^{48}$.

Ausschlaggebend war eine im Grunde rein allegorische Illustration mit der Frontalansicht einer nackten Frau, die kraftlos in den Fängen einer den Tod darstellenden schwarzen Gestalt liegt ${ }^{49}$. Als ironische Antwort auf seine Verurteilung veröffentlichte die Zeitschrift wenig später dasselbe Motiv, diesmal jedoch als Rückenansicht, wodurch die nackte Frau kaum mehr zu sehen war ${ }^{50}$. Damit aber war diese Episode, was bisher unbeachtet blieb, noch keineswegs abgeschlossen: Am 3. November 1889 erschien in Le Courrier français eine Titelillustration Legrands mit der Widmung $\grave{A}$ la presse (Abb.1): Eine nackte Frau wird auf einer zur Folterbank umfunktionierten Druckerpresse von einem Zwitterwesen aus Fledermaus und Eule gequält. Gefesselt und geknebelt, kann sie sich nicht wehren; die Laterne, mit der sie Licht verbreiten sollte, ist ihr aus der Hand gefallen. Wie zum Hohn heißt der Untertitel des Blattes Fiat lux. Der hier stattfindende Kampf der Finsternis gegen das Licht scheint bereits entschieden. Die nackte Frauengestalt verkörpert per se die unterlegene Wahrheit in ihrer traditionellen Gestalt der Nuda Veritas ${ }^{51}$. Legrands Darstellung bezieht sich explizit auf die Titelillustration der Erstausgabe von Le Courrier français, die am 10. November 1884 erschienen war (Abb.2): Das Bild zeigt den Moment, in dem die nackte Wahrheit gerade dem Brunnen entstiegen ist und mit Fackel und Spiegel das Licht der Wahrheit verbreitet. Überschrieben ist die Illustration mit den Worten Notre programme. Die fast fotorealistische Gestaltung des Körpers der Wahrheit wird zum unmittelbaren Symbol für das Anliegen, die Gesellschaft so darzustellen, wie sie ist. Fast scheint es, als wäre eine reale Frau wie in einer Collage mit den allegorischen Attributen ausgestattet worden. Dieses ironisch-erotische Spiel steht exemplarisch für die Doppelbödigkeit der Gesellschaftskarikatur in Le Courrier français. Der Betrachter sieht sich unwillkürlich als Voyeur ertappt. In einem allegorischen Kontext ist die Nacktheit traditionell zwar erlaubt, doch nichtsdestoweniger nimmt Legrands gepeinigte Wahrheit auf seine als

47 Albert, Presse, S. 245. Dazu auch Goldstein, Censorship, S. 235; Lethève, Caricature, S. 36f.

48 Dazu ausführlich Goldstein, Censorship, S.244-246.

49 Louis Legrand, Prostitution, in: Le Courrier français, 24.6.1888; Goldstein, Censorship, S. 246, Abb. 71.

50 Louis Legrand, Prostitution, in: Le Courrier français, 7.4.1889.

51 Zur Allegorie der Wahrheit ausführlich Kap.8.2. 

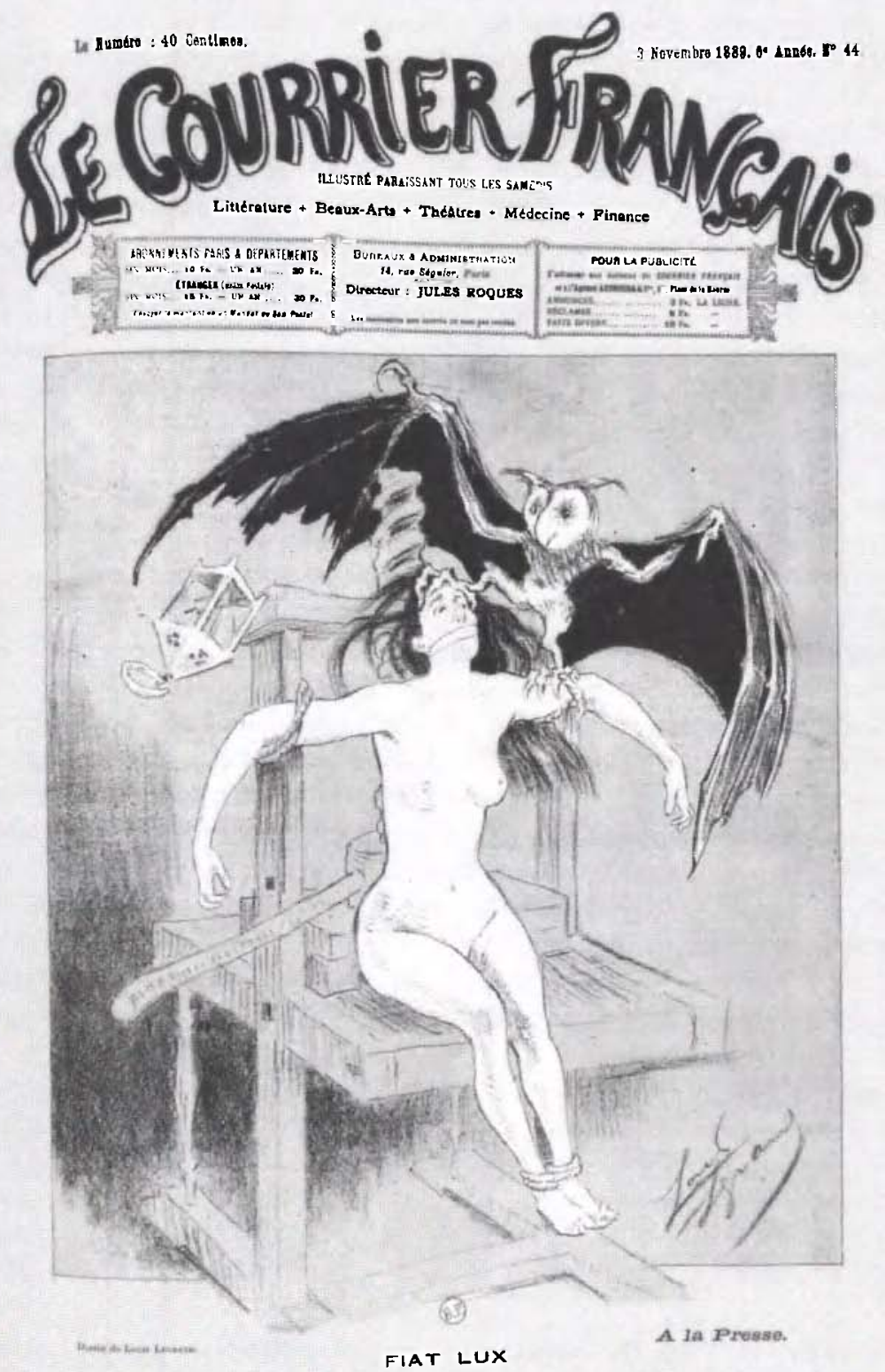

Abb. 1 Louis Legrand: À la presse. Fiat lux, in: Le Courrier français, 3.11.1889. Bibl. Forney, Paris. 


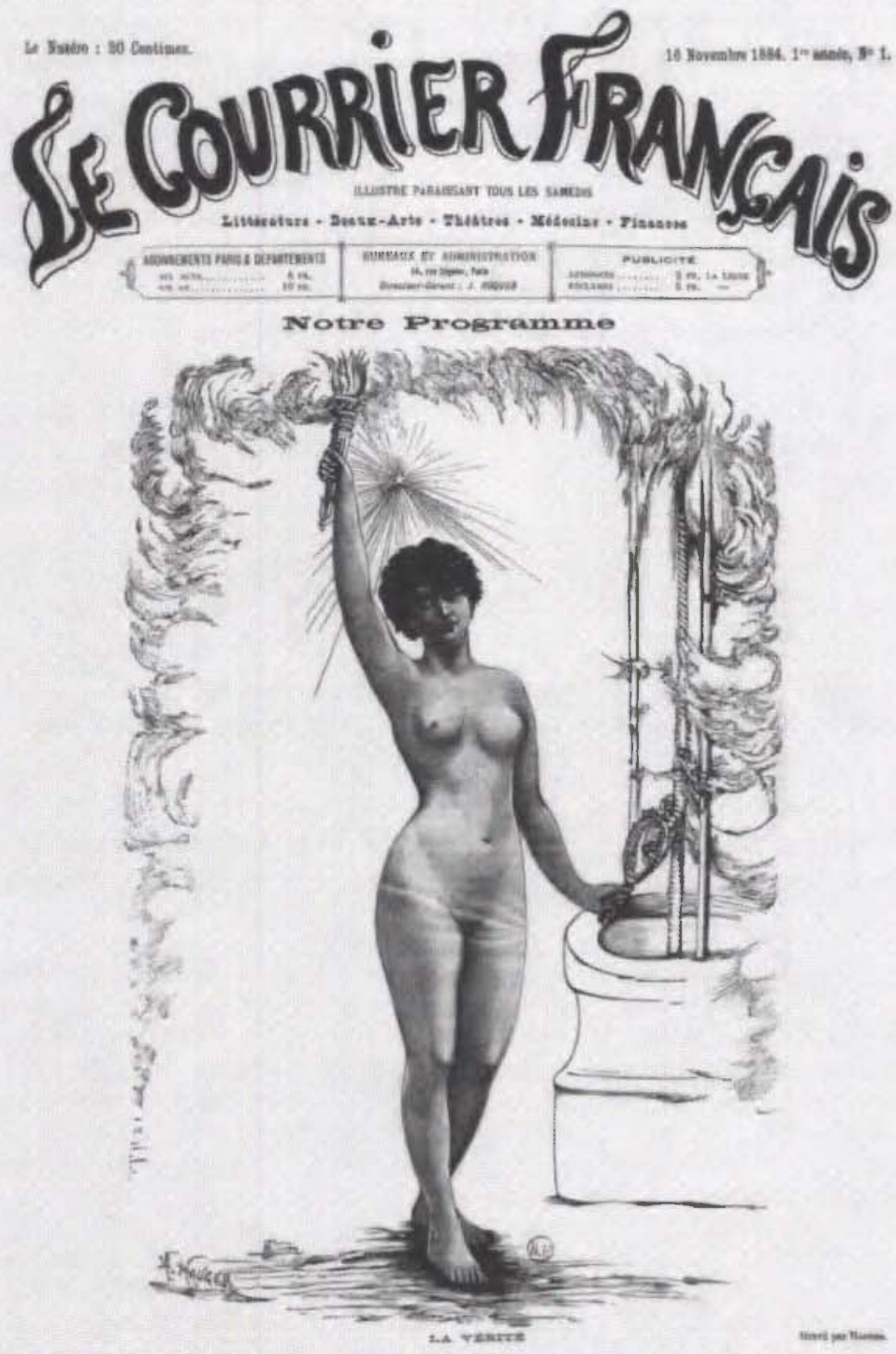

Abb. 2 Habert: Notre programme. La Vérite, in: Le Courrier français, 10.11.1884. Bibl. Forney, Paris. 
anstößig empfundene Prostituierte direkt Bezug: Die Wahrheit ist in jedem Falle die Verliererin, wird ausgebeutet und instrumentalisiert, unter dem Vorwand, daß sie gegen die guten Sitten verstößt. Zudem muß sie sich Zwängen unterwerfen, sich zur Schau stellen lassen und verliert so ihre Würde.

Dieses Beispiel verdeutlicht den Wandlungsprozeß, den die Karikatur nach 1881 durchlief: Soziale und gesellschaftliche Anliegen vermischten sich immer stärker mit politischen Problemen, wobei soziale Kritik schnell selbst zum Politikum wurde. Der wichtigste Grund hierfür war, daß die herrschenden Schichten nun selbst das System der Republik repräsentierten und die Republik für vielerlei Mißstände die unmittelbare Verantwortung übernehmen mußte. Die Kritik an dieser real existierenden Republik führte somit automatisch zu einer Erweiterung des Themenspektrums der Karikatur.

Wichtig erscheint in diesem Zusammenhang die von Ursula Koch vorgenommene Korrektur von Jones' Definition des âge d'or, die die Jahre von 1881 bis 1914 als »das goldene Zeitalter der illustrierten satirischen Presse im eigentlichen $\operatorname{Sinn} \ll^{52}$ bezeichnet:

Zwischen 1890 und 1910 erschienen auf dem Pariser Zeitschriftenmarkt circa 250 Titel. Charakteristisch war nicht allein die Vielfalt der Typen und Mischtypen, sondern auch der Meinungen. Denn: nahezu jede politische oder ideologische Richtung verfügte jetzt über ein ihr nahestehendes Witzblatt, wenn nicht über mehrere ${ }^{53}$.

Ebenso charakteristisch für diese Epoche ist zweifellos auch die Tatsache, daß in führenden Satirezeitschriften politische Karikaturen zahlenmäßig hinter die Gesellschaftssatire zurücktraten. Der Grund dafür ist in dem hohen Konkurrenzdruck des dicht besetzten Marktes zu suchen, in dem politisch engagierten ebenso wie stark spezialisierten Zeitschriften oft nur eine geringe Lebensdauer beschieden war ${ }^{54}$. Zurückgenommene, mäßig frivole Sittenkari-

52 Ursula E. KoсH, Zwischen Narrenfreiheit und Zwangsjacke: Das illustrierte französische Satire-Journal 1830-1881, in: Rolf Reichardt (Hg.), Französische Presse und Pressekarikaturen., Mainz 1992, S.43. Auch ThlLIER, Traits indécis, S. 88 schreibt, mit dem Gesetz von 1881 habe "véritablement l'âge d'or de la presse satirique « begonnen. Zum technischen Fortschritt der eine ebenfalls unabdingbare Voraussetzung für diesen Boom war, vgl. ausführlich Louis CharLet, Robert Ranc, L'évolution des techniques, in: Bellanger, Histoire, S.61-132. Vor allem die um 1880 eingeführte Photogravur ermöglichte die schnelle Reproduktion von Klischees.

${ }_{53} \mathrm{KoCH}$, Narrenfreiheit, S. 43. Damit wird das goldene Zeitalter der satirischen Presse gleichgesetzt mit der von Albert, Presse, S.239, zwischen 1880 und 1914 angesetzten apogée de la presse. Die bedeutenderen Magazine bildeten in Paris ein regelrechtes karikaturistisches Viertel, das sich um die Rue du Croissant nahe der Börse (II. Arrondissement) gruppierte, wo 25 Redaktionen ihren Sitz hatten. Vgl. JoNES, De Daumier à Lautrec, S. 18-20. Zur Korrektur von Jones' zeitlicher Eingrenzung auch in künstlerischer Sicht vgl. Raymond Bachollet, La revue satirique illustrée, in: Le Collectionneur français 154 (1979), S. 12: »la période qui s'étend de 1880 à la Première Guerre mondiale est celle qui voit apparaître un nombre invraisemblable de feuilles satiriques illustrées d'une exceptionnelle qualité

54 Darunter so spezielle Titel wie Le Bon Bock (Februar-Juli 1885) oder Le Bon Buveur (Juni-Juli 1888), die sich der Verteidigung der nationalen Trinkkultur verschrieben hatten. 
katur erwies sich als probates Mittel, um eine möglichst breite Rezipientenschicht anzusprechen. Exemplarisch dafür steht etwa die 1894 gegründete Le Rire, in der die politische Karikatur einen vergleichsweise geringen Raum einnimmt, ohne daß damit ein Niedergang bezüglich der satirischen Schärfe des Einzelbildes verbunden wäre. Diese Tendenz kennzeichnet auch die seit 1901 erscheinende Assiette au beurre, die in ihren je einem bestimmten Thema gewidmeten Heften Politik und Unterhaltung gleichermaßen zu ihrem Recht kommen lie $\beta^{55}$. Parallel zu der explodierenden Zahl an illustrierten satirischen Zeitschriften fand die Karikatur ab den späten 1880er Jahren - wenn auch zunächst nur sehr vereinzelt - Eingang in die Tagespresse ${ }^{56}$. Damit war die Karikatur Teil der seit 1880 zu beobachtenden Strategie, die eine Popularisierung der einst einer Elite vorbehaltenen Zeitungslektüre anstrebte ${ }^{57}$, nachdem durch die zunehmende Alphabetisierung im Rahmen der instruction obligatoire das potentielle Publikum immer größer geworden war ${ }^{58}$. Die Illustration weckte allgemein auch das optische Interesse der Käufer ${ }^{59}$ : Der Rezi-

$55 \mathrm{Zu}$ Le Rire vgl. Raymond BACHOLLET, "Le Rire « avant la Première Guerre mondiale, in: Le Collectionneur français 157 (1979), S.13-16. Die auf selbständige Textbeiträge voll und ganz verzichtende L'Assiette au beurre ist zweifellos die am besten untersuchte satirische Zeitschrift dieser Epoche überhaupt. Dazu Élisabeth und Michel DixmiER, L'Assiette au beurre. Revue satirique illustrée, Paris 1974; Michel Dixmier, L'Assiette au beurre, revue contestataire et artistique, in: Jules Grandjouan: créateur de l'affiche politique illustrée en France, S. 112-127; Gisèle LAMBERT, L'Assiette au beurre. Les illustrateurs de l'Assiette au beurre, 2 Bde., Mémoire de l'école du Louvre 1975; Dies., L'Assiette au beurre, in: Nouvelles de l'estampe 23 (1975), S.7-17; Sepp Hiekisch-PICARD, Die Zeitschriften »Gil Blas illustré«, "Le Rire» und "L'Assiette au beurre«, in: Gerhard LANGEMEYER ( $\mathrm{Hg}$.), Bilderwelten II, Dortmund 1986, S. 27-33.

56 LETHÈve, Caricature, S.54: Den Anfang machte im Jahr 1887 die Zeitung La Nation. Zuvor hatte die von Victor Hugo gegründete Zeitung Le Peuple souverain im Jahr 1872 bereits zwei Karikaturen von Daumier und André Gill veröffentlicht.

57 Dazu Delporte, Presse, S.100f.: »Entre la fin du Second Empire et la veille de la Grande Guerre, la place du journal dans l'univers quotidien a complètement changé. La grande presse populaire a brisé les clivages qui dominaient encore vers 1880 . En 1914, non seulement le quotidien est devenu un objet de consommation courante, mais les éléments qui, encore vers 1880 , marquaient une frontière infranchissable entre public des élites et public populaire sont tombés: prix, mode d'achat, format se sont unifiés. Les trois quarts des quotidiens sont vendus à un sou, au numéro, sur grand format $«$. Zu den Elementen, die eine breite Schicht für die Zeitungslektüre gewannen, gehörten etwa der Fortsetzungsroman oder die faits divers, die allmählich die Funktion der canards und ihrer Sensationsberichte übernahmen (ibid., 102). Dazu auch MarTiN, Médias, S. 76-78. Ermöglicht wurde die Aufnahme der Karikatur in die Tageszeitung nicht zuletzt durch fortschrittliche Techniken, die den gleichzeitigen Druck von Bild und Text ermöglichten. Vgl. TILLIER, Traits indécis, S.89.

58 Mollier, Parfum.

${ }^{59}$ DelPorte, Presse, S. 108. Gleichzeitig hielt auch die illustrierte Werbung zunehmend in die Zeitungen Einzug. Vgl. dazu Gilles Feyel, Presse et publicité en France (XVIII ${ }^{e}$ et $X X^{e}$ siècles), in: Revue historique 310 (2003), S. 837-868. Um die Jahrhundertwende wurden auch illustrierte Sonntagsbeilagen immer häufiger, die allerdings kaum Karikaturen enthalten. 
pient von Karikaturen war hierbei also in erster Linie Leser ${ }^{60}$. Daß sich mit der technischen Reproduzierbarkeit künstlerischer Erzeugnisse auch deren Verhältnis zur Masse änderte, stellte schon Walter Benjamin fest ${ }^{61}$. Der Einzug der Karikatur in die quotidiens bereicherte diese das 19. Jahrhundert prägende Entwicklung zusätzlich um die Faktoren Quantität und Geschwindigkeit: Gegenüber den meist wöchentlich erscheinenden Satiremagazinen besaß die Tageszeitung einen nicht zu unterschätzenden Aktualitätsvorsprung ${ }^{62}$, zudem erweiterte sich aufgrund der viel höheren Auflagen der Kreis der möglichen Rezipienten erheblich.

Die Karikatur, und besonders die politische, sah sich jedoch auch hier vor Probleme gestellt:

Le caractère violemment polémique des caricatures sied mal à une presse soucieuse de plaire à un large public; toutefois, au-delà des excès qui se manifestèrent alors dans les compositions graphiques, l'affaire Dreyfus a montré l'attraction exercée par ce mode de communication ${ }^{63}$.

Nicht zufällig aber spielte die Karikatur im Rahmen der Dreyfusaffäre in der nicht-satirischen Tagespresse eine nicht zu unterschätzende Rolle ${ }^{64}$. Zeitungen, die sich für eine der beiden Seiten entschieden hatten, weisen eine hohe Dichte an äußerst bedeutsamen Karikaturen auf. Dazu zählen im Lager der dreyfusards etwa Le Siècle ${ }^{65}$ oder Le Petit Bleu de Paris, auf der Gegenseite das tendenziell antisemitische Blatt L'Intransigeant. Das Massenblatt Le Figaro dagegen veröffentlichte trotz seiner gegen Dreyfus gerichteten Grundhaltung Arbeiten von Karikaturisten beider Lager. Eine Tendenz zur gedämpften Neutralität in dieser das ganze Land in Atem haltenden Angelegenheit prägt auch die Zeitschrift Le Rire ${ }^{66}$. Man muß hier also wohl von anderen, subtile-

${ }^{60}$ Dadurch unterscheidet sich die Rezeption von der meist in Periodika integrierten Bildpublizistik des ausgehenden 19. Jahrhunderts von der frühneuzeitlichen, die von einem in hohem Maße analphabetischen Publikum aufgenommen wurde.

61 Walter Benjamin, Das Kunstwerk im Zeitalter seiner technischen Reproduzierbarkeit, in: Ders., Gesammelte Schriften, Bd. 1, 2, Frankfurt a. M. 1974, S. 459.

62 Fuchs, Karikatur, S.352, sieht in dem Vordringen der Karikatur in die Tageszeitungen sogar den wichtigsten Fortschritt der Gattung überhaupt: »Der größte Sieg, den die moderne Karikatur in Frankreich errungen hat, ist die Eroberung der ernsten Tagespresse. Die Tagespresse hat aber nicht nur vermöge ihrer Mittel die ersten Kräfte in ihre Dienste gespannt, Forain, Caran d'Ache, Hermann Paul, usw., sondern sie hat auch, und gerade das ist das Wichtige, in der Aktualität der Witzblattpresse für alle Zeiten den Rang abgelaufen. Was eben erst aus der Hand des Zeichners hervorging, ist kaum zwölf Stunden später in der Hand von Hunderttausenden«.

63 Ibid.

64 Zur Rolle des Bildes in der Dreyfusaffäre vgl. auch Prochasson, LAffaire, S.238f.: "L'image a ainsi contribué à créer ou à nourrir des opinions, seules juges des joutes oratoires durant l'Affaire. Au tournant du siècle, elle acquiert une nouvelle part de l'autonomie, dispose de ses codes propres et développe ses références. Elle se trouve ainsi au centre d'une culture de masse en voie de constitution $\%$.

65 Die Bildbeiträge von Ibels wurden zudem im Album du siècle veröffentlicht.

66 Dazu Bachollet, »Le Rire «, S. 14. 
ren Formen der Zensur ausgehen, die sowohl innerhalb der Redaktionen als auch in den Köpfen der Künstler stattfand. Auch hier sollte indessen genau unterschieden werden: Das sich zunehmend aufsplitternde politische Spektrum fand seinen Widerhall naturgemäß auch bei den Künstlern selbst und erschwerte die Identifikation eines gemeinsamen Gegners oft erheblich. Prorepublikanische und antiklerikale Überzeugungen, die bis 1880 verbindend gewesen waren, reichten als gemeinsame Grundlage nicht mehr aus. Dies zeigte sich erstmals bei der Rezeption der Boulangeraffäre, und, in noch wesentlich stärkerem Maße, im Fall Dreyfus, der nicht zuletzt eine vorübergehende Spaltung des Künstlerkreises am Montmartre nach sich zog67. Dieses ungemein produktive Milieu spiegelt auch den unglaublichen stilistischen Reichtum der Karikatur im ausgehenden 19. und frühen 20. Jahrhundert wider ${ }^{68}$. Die hochinteressanten Wechselwirkungen zwischen künstlerischer Avantgarde und Karikatur sind ein äußerst wichtiger Faktor, der in seinen Auswirkungen noch keineswegs hinreichend erforscht wurde ${ }^{69}$. Die im Entstehen begriffene künstlerische Moderne mit ihrer neuartigen, stärker abstrahierenden Wirklichkeitskonstruktion ließ sich schon im Frühstadium des Impressionismus von der stilistischen Sprache der skizzenhaften Pressezeichnung inspirieren $^{70}$. Die gegenseitige Befruchtung zeugt in hohem Maße auch von dem Einfluß, den die stetig wachsende Presselandschaft auf die sich verändernden Sehgewohnheiten ausübte ${ }^{71}$. Die Maler-Karikaturisten gehörten da-

67 Dazu Gervereau, S'engager, S. 197: „De cette façon, il apparaît que si l'affaire Dreyfus a mobilisé les passions des dessinateurs en 1898-1899, elle n'en a pas pour autant réellement divisé le milieu, qui continue de se côtoyer dans divers organes de presse«. Im übrigen erwies sich die Solidarität der Künstler untereinander als tragfähiges Netz. Fuchs, Karikatur, S.358, berichtet, daß der Karikaturist Blass nach seiner plötzlichen Entlassung aus den Diensten des legitimistischen Magazins Le Triboulet allein durch die Unterstützung der Kollegen vom Montmartre mit seiner Familie überleben konnte.

$68 \mathrm{Vgl}$. dazu allg. Sepp Hiekisch-PICARD, Künstlerische Tendenzen der französischen satirischen Illustration um 1900, in: LANGEMEYER, Bilderwelten II, S. 18-26.

${ }_{69} \mathrm{Vgl}$. zu den vielfältigen Beziehungen der Künstler untereinander etwa Phillip Dennis Cate, Patricia Eckert Boyer, The Circle of Toulouse-Lautrec. An Exhibition of the Work of the Artist and his Close Associates, Ausstellungskatalog. Rutgers 1986. Zu den MalerKarikaturisten vgl. Ralph ShIKes, Steven Heller, The Art of Satire. Painters as Caricaturists and Cartoonists from Delacroix to Picasso, New York 1984. Zu den Wechselwirkungen zwischen Malerei und Karikatur im Werk von Camille Pissarro und Théophile Alexandre Steinlen vgl. Daniela KNeısst, Réflexions sur la Ville Lumière: le symbolisme de l'éclairage artificiel dans la peinture et la caricature à la fin du XIX ${ }^{\mathrm{e}}$ siècle, in: Ridiculosa 11 (2004), S.235-245.

70 Joel IsAaCson, Impressionism and Journalistic Illustration, in: Arts Magazine 56 (1982), S. 95-115.

${ }^{71}$ Zum Wahrnehmungsproblem des ausgehenden 19. Jahrhunderts vgl. besonders Kap. 8.2.2. Zur Bevorzugung graphischer gegenüber malerischen Techniken für die Reproduktion der sich stetig verändernden Wirklichkeit vgl. auch Richard Thомson, Styling the City. Observation and Perception in Print Albums of the 1890s, in: Phillip Dennis Care u. a. (Hg.), Prints abound. Paris in the 1890s, Washington, London 2000, S.50: »The print - its graphic range quickly adaptable to the nuances of the now; its scale, immediacy, and 
bei ganz unterschiedlichen künstlerischen Strömungen an, darunter, um nur einige zu nennen, die Pointilisten Paul Signac, Maximilien Luce oder Lucien Pissarro, die den Nabis zugeordneten, aber untereinander stilistisch kaum vergleichbaren Künstler Félix Vallotton ${ }^{72}$ und Henri-Gabriel lbels ${ }^{73}$ - letzterer auch bekannt als Nabi journaliste - oder der treffend als »poetischer Realist« bezeichnete gebürtige Schweizer Théophile-Alexandre Steinlen ${ }^{74}$. Besonders Steinlen muß als der vielleicht wichtigste Vertreter der neuen sozialen Karikatur gelten, in der die bedrückende Realität der untersten Schichten ein ebenso ausdrucksstarkes wie ästhetisch ausgefeiltes Sprachrohr fand ${ }^{75}$.

Allen diesen Künstlern gemeinsam aber war ein gesteigertes Interesse an den sozialen Prozessen der Großstadt, deren neue Erfahrungswelten sie mit veränderten Techniken darstellen und interpretieren wollten. Das gesellschaftliche Potential dieser Prozesse spiegelte sich naturgemäß auch in der politischen Karikatur und trug zur Ausbildung einer neuen, sozialpolitischen Bildsprache bei. Zahlreiche Beispiele für diese Wechselwirkung finden sich in den Arbeiten der dreyfusards.

Gesellschaftlicher Veränderungswille brachte auch unter den Künstlern radikalere Persönlichkeiten hervor, wobei vor allem der gewerkschaftlich engagierte Jules Grandjouan zu nennen ist, dem die sozialistische Agitationskarikatur entscheidende Anstöße verdankte ${ }^{76}$.

availibility making it a close cousin to caricature, was the ideal medium for conveying the febrile modernity of fin-de-siècle France «.

${ }^{72} \mathrm{Zu}$ Vallotton vgl. Félix Vallotton: gravures sur bois. Préface de Manuel Jover, Ausstellungskatalog, Monaco 1993; Ashley Sr. JAMES, Vallotton dessinateur de presse, Paris 1979. Die Holzschnitte und Lithographien von Vallotton fallen durch die Ausschließlichkeit des Kontrastes zwischen Schwarz und Weiß auf. Zwar nutzt er dies in seinen politischen Beiträgen während der Dreyfusaffäre durchaus symbolisch, doch in erster Linie muß hier auf den enormen Einfluß der japanischen Holzschnittkunst im Frankreich des späten 19. Jahrhunderts verwiesen werden, wobei Vallotton sich offenbar in erster Linie von den traditionellen Darstellungen des No-Theaters inspirieren ließ.

${ }^{73} \mathrm{Zu}$ Ibels vgl. J.-H. O'Toole, Henri-Gabriel Ibels: Nabi journaliste, in: Gazette des beaux-arts 99 (1992), S.31-38; Anne-Marie Sauvage, Henri-Gabriel Ibels: le Nabi journaliste: l'œuvre graphique des années 1890, in: Nouvelles de l'estampe 129 (1993), S.25-33.

${ }^{74}$ Peter DitTMar, Théophile Alexandre Steinlen. Ein poetischer Realist in der Epoche des Jugendstils, Zürich 1984.

75 Zum Begriff der sozialen Karikatur vgl. Fuchs, Karikatur, S. 424: »Mit der wachsenden Einsicht, daß die Arbeit nicht mehr schöne, erhebende Lebensaufgabe ist, sondern für die große Masse der Menschen Last und Fluch bedeutet, entstand die moderne sogenannte soziale Karikatur, die Elendskarikatur, die die Last und den Fluch der Arbeit mit entsprechend düsteren Farben illustrierte

${ }^{76}$ Darüberhinaus gilt Grandjouan als der Begründer des illustrierten politischen Plakats in Frankreich. Vgl. dazu Jules Grandjouan: créateur de l'affiche politique illustrée en France, Ausstellungskatalog, hg. v. Musée d'Histoire contemporaine, Paris 2001. Das illustrierte politische Plakat im eigentlichen Sinne ist dabei von den bis Ende des 19. Jahrhunderts vorherrschenden Werbeplakaten für politische Presseorgane zu unterscheiden, auch wenn die politische Aussagekraft dieser Informationsträger außer Frage steht. (Vgl. dazu etwa Ogés Farbplakat für die Zeitung La Lanterne anticléricale, Kap.5.3.) 
Neben der politischen und künstlerischen Überzeugung aber spielten bei der Themenwahl die Notwendigkeiten des wirtschaftlichen Überlebens eine mindestens genauso große Rolle: Mit der Zahl der Publikationsorgane wuchs naturgemäß auch die Anzahl der Künstler. Um die Wende zum 20. Jahrhundert nahm der Strom der Maler nach Paris in nie gekanntem Maße zu. Die Zahl der am Salon des indépendants teilnehmenden Künstler sprechen für sich: Stellten noch im Jahr 1900 nur 164 Künstler ihre Werke aus, so waren es ein Jahr später bereits 1012, eine Zahl, die sich 1905 mit 4209 Teilnehmern vervierfachte und bis 1909 auf 6701 Aussteller anwuchs ${ }^{77}$. Der Marktwert vieler dieser Neuankömmlinge, die sich zwangsläufig der Presseillustration zuwandten, war häufig gering, das künstlerische Potential wurde, gerade im politisch-satirischen Bereich, wohl oft genug aus wirtschaftlichen Erwägungen den Wünschen der Auftraggeber unterstellt:

Many contributed satirical sketches or caricatures, occasionally even strongly political drawings, to the journaux amusants،, especially Le Rire or Le Courrier français, for which they were paid sometimes generously, other times not at all. Many managed to scrape by, but protest was in the air. The most social-minded of the artists often turned toward anarchism as the political expression of their reaction against the injustices they observed and the frustrations of their own condition ${ }^{78}$.

Der Unterschied zwischen Anspruch und Wirklichkeit wurde auch von vielen etablierten Karikaturisten oft als nicht minder groß empfunden, zumal nicht wenige ihre Abhängigkeit von der Pressezeichnung als persönliches Scheitern empfanden ${ }^{79}$.

Die eigene Meinung geriet dabei nicht selten ins Hintertreffen: Die teils erstaunliche Anzahl von Pseudonymen verweist oft auf die Tätigkeit eines Künstlers für einander politisch entgegengesetzte Lager. Ob diese Haltung politischer Gleichgültigkeit, finanzieller Berechnung oder schlicht der Resignation entsprang, kann meist nur vermutet werden ${ }^{80}$. Verwiesen sei hier

77 Ralph Shikes, Five Artists in the Service of Politics in the Pages of "L'Assiette au beurre«, in: Henry A. Mrllon, Linda Nochlin (Hg.), Art and Architecture in the Service of Politics, Boston 1978, S. 162.

78 Ibid.

79 Zur vagen Definition des Pressezeichners Ende des 19. Jahrhunderts vgl. Thlurer, Traits indécis, S.99:»Le dessinateur de presse jouit d'un statut particulièrement ambigu, procédant confusément de l'illustrateur médiocre, de l'artiste raté, du crayonneur vénal, du journaliste de rang inférieur, du propagandiste acharné ou de la personnalité engagée«. Die Entwicklung zum (Bild-)Journalismus durchlief dieser Beruf erst zwischen 1920 und 1930. Dazu Christian Delporte, Le dessinateur de presse, de l'artiste au journaliste, in: Vingtième Siècle 35 (1992), S.29-42. Zu der gespaltenen Haltung vieler hauptberuflicher Karikaturisten zu ihrem eigenen Tun vgl. Lethève, Caricature, S. 40: »Pour les artistes qui ont poursuivi leur carrière dans l'image satirique, il semble bien que beaucoup aient difficilement accepté l'abandon d'un idéal plus ambitieux. Rares sont ceux qui ne se sont pas au moins essayé à la grande peinture, quitte s'ils n'y ont pas réussi à se tenir pour des ratés, comme ces excellents acteurs comiques qui ne se consolent pas de renoncer à la tragédie«. ${ }^{80}$ Eine Sozialgeschichte der Karikaturisten im späten 19. Jahrhundert ist noch nicht geschrieben und würde angesichts der überwältigenden Zahl von Künstlern, deren persön- 
etwa auf das Beispiel von Lemot, der unter seinem bürgerlichen Namen die wichtigsten Bildbeiträge zu dem kirchlichen Magazin Le Pèlerin lieferte und unter dem Pseudonym »Uzès « unter anderem für das libertäre Satiremagazin Le Chat noir arbeitete. Der Schüler des Starkarikaturisten André Gill betrachtete sich dabei selbst als künstlerisch gescheitert $^{81}$. Interessant ist auch der Fall von Valère Morland, der unter dem Pseudonym »Bobb« für La Silhouette gegen Dreyfus gerichtete Bilder schuf, und als »Kab« für die in Lyon erscheinende Comédie politique als dreyfusard in Erscheinung trat. Selbst bei sehr gut erforschten Künstlern wie Émile Cohl, der aufgrund seiner Pioniertätigkeit auf dem Gebiet des Animationsfilms starke Beachtung fand, blieben Einzelheiten über die politische Entwicklung im Unklaren. Dies gilt auch in diesem speziellen Fall hinsichtlich des im Rahmen der Dreyfusaffäre hervortretenden Antisemitismus: Unter dem Pseudonym »Chanteclair « arbeitete Cohl für das Blatt La Libre Parole illustrée, die Satirebeilage der extrem antisemitischen Zeitung La Libre Parole, ohne dabei seinerseits in wirklichen Antisemitismus zu verfallen. $\mathrm{Ob}$ diese Mitarbeit aus zumindest annähernder politischer Zustimmung oder allein finanziellen Gründen erfolgte, muß wie so oft im Dunkeln bleiben ${ }^{82}$. Auch im Fall von Théophile Alexandre Steinlen, der für Le Chambard socialiste, die erste illustrierte Arbeiterzeitschrift, unter dem Namen "Petit Pierre a arbeitete, muß von einer Verschleierung ausgegangen werden, die weniger radikale Kunden nicht abschrecken und vor eventueller Strafverfolgung schützen sollte - ebenso wie seine ebenfalls gelegentlich auftauchende Signatur »Jacques Caillou«. Anders als bei dieser eher halbherzigen Tarnung verhielt sich der Fall bei Lucien Pissarro, dem Sohn von Camille Pissarro, der ebenso wie sein Kollege Maximilien Luce seine Bildbeiträge für die anarchistische Zeitschrift Le Père peinard aus Angst vor Repressalien fast nie signierte ${ }^{83}$.

liches Schicksal oft völlig im Dunkeln liegt, auch eine äußerst diffizile Aufgabe darstellen. Hilfreich für die Suche nach der politischen Position einzelner Karikaturisten ist das Lexikon von Solo, SAINT-MARTIN, 5000 dessinateurs, das auch aufschlußreiche Zitate enthält. 81 Ibid., S. 388: »Aujourd'hui, je fais des illustrations pour les petits bouquins, c'est gentil, ça fait bouillir le pot-au-feu - mais enfin, ce n'est pas du grand art, ou même de l'art moyen«. (A. LEMOT, 1885.)

82 Donald Crafton, Émile Cohl, Caricature, and Film, Princeton 1990, S.60-63. Auch bei den direkt für eine Seite eintretenden Künstlern scheint selbst in dieser heiklen Frage politische Gegnerschaft und kollegiales Miteinander nicht unvereinbar gewesen zu sein: Ibels, wichtigster Zeichner von Le Sifflet, der wichtigsten Satirezeitschrift der dreyfusards und Forain, Gründer des die gegenteilige Fraktion vertretenden Psst!... sollen trotz ihres unablässig ausgefochtenen Bilderkriegs zur selben Zeit privat befreundet gewesen sein. Vgl. Inventaire du fonds français. Graveurs. Après 1800, Paris, BnF, Bd.11, S.19. Zu Forain vgl. Jacqueline MAGNE, Forain témoin de son temps. Une satire sociale, morale et politique, Marseille 1973; Dies., Forain et l'affaire Dreyfus, in: Nouvelles de l'estampe 8 (1973), S.9-13; Bertrand ThlLier, Virulences verbales et graphiques au cœur de l'affaire Dreyfus: le Psst $\ldots$.. de Forain et Caran d'Ache, in: Ridiculosa 6 (1999), S. 183-198.

83 Dazu Denise Bazetoux, Luce, la politique et la presse, in: Dies., Jean Bouin-Luce, Maximilien Luce. Catalogue de l'œuvre peint, La Celle-Saint-Cloud 1986, Bd.1, S. 146. 
Diese wenigen Beispiele verdeutlichen, daß die Karikatur auch jenseits der eigentlichen Zensur keineswegs eine völlig >freie< Kunstrichtung wurde.

Zweifellos ist das Verhältnis von künstlerischem Anspruch, politischer Überzeugung und Zugeständnissen an den Markt ein bestimmender, wenn auch schwer faßbarer Faktor. Für den politischen Gehalt der Ende des 19. Jahrhunderts in den Vordergrund tretenden sozialkritischen Karikatur scheint indessen besonders ein Aspekt von zentraler Bedeutung zu sein: Für die oft selbst von wirtschaftlicher Unsicherheit bedrohten Künstler war sie ein Mittel, die Kritik an den bestehenden Verhältnissen über das politische Tagesgeschehen hinaus in den Bereich gesellschaftlicher Mißstände auszuweiten, von denen sie selbst betroffen waren. Soziale Kritik wurde so zum unmittelbaren politischen Protest. Die spezifische Eigenschaft der sozialen Karikatur, niemals den leidenden Menschen zu karikieren, sondern seine Situation in drastischer Art und Weise anzuprangern und zur Metapher für das Elend an sich zu erklären, öfnet auch die Grenzen der politischen Karikatur und stellt die Frage nach ihrem Objekt neu. Eine strikte Trennung zwischen gesellschaftlicher und politischer Bildsatire, wie sie Michaela Siebe ${ }^{84}$ vorschlägt, erscheint speziell für den Aktionsrahmen der vorliegenden Arbeit als wenig angemessen, da ein derartiger Filter viele aussagekräftige Interaktionen zwischen Politik und Alltagskultur ausblenden würde. Für eine mehrfach reflektierte Herangehensweise an das Phänomen des republikanischen Lichts und seine unterschiedlichen Repräsentationen wäre dies fatal.

Soziale Kritik nämlich reflektiert in der Karikatur und kritischen Grafik des späten 19. und frühen 20. Jahrhunderts stets auch das Verhältnis zwischen Anspruch und Wirklichkeit der Republik und ihrer Rolle als Vermittlerin der lumières in all ihren Erscheinungsformen.

${ }^{84}$ Dazu Michaele SiEBE, Von der Revolution zum nationalen Feindbild. Frankreich und Deutschland in der politischen Karikatur des 19. Jahrhunderts. "Kladderadatsch» und "Charivari«, Münster 1995, S. 16: Siebe unterscheidet zwischen "Gesellschaftssatire «, die sich mit Themen wie Mode, Sitten, Alttagsereignissen und kulturellen Verhaltensmustern befaßt, sowie "politischer Karikatur «: Letztere »bezieht sich explizit auf das aktuelle Tagesgeschehen und nimmt dazu Stellung «. Diese Unterscheidung übernimmt auch Dieter Grünewald, Zwischen Kunst und Journalismus. Politische Karikaturen, in: Ders. (Hg.), Politische Karikatur. Zwischen Journalismus und Kunst, Weimar 2002, S.9-24, der den Begriff der politischen Karikatur jedoch auf Darstellungen ausweitet, deren Funktion es sei, "politische Positionen metaphorisch zu thematisieren «. Für Siebes Untersuchungsgebiet, nämlich die Entstehung national geprägter Feindbilder in Deutschland und Frankreich während des II. Empire, ist dieses Schema sicherlich relativ unproblematisch. Auf dem Feld innenpolitischer Auseinandersetzungen tauchen hier jedoch große Probleme auf, da in Zeiten der Zensur oft gerade vordergründig unpolitische Themen als Tarnung für die Kritik an den politischen Verhältnissen dienen. Dies zeigt etwa das in Kap.3.2.2. aufgeführte Beispiel von Daumiers Sequenz zu Babinets Verdunkelungstheorie. 
